\title{
EFFICIENT MODELLING OF COMPOSITE BUILDING RESPONSE TO COMPARTMENT FIRES
}

\author{
Zhaohui Huang ${ }^{1, *}$, Ian Burgess ${ }^{2}$ and Roger Plank ${ }^{3}$ \\ ${ }^{1}$ Lecturer, Department of Civil \& Structural Engineering, University of Sheffield, S1 3JD, UK. \\ *(Corresponding author: Email: z.huang@sheffield.ac.uk, Tel: +44 (0) 114 2225710, Fax: +44 (0) 114 2225700) \\ ${ }^{2}$ Professor, Department of Civil \& Structural Engineering, University of Sheffield, S1 3JD, UK. \\ ${ }^{3}$ Professor, School of Architectural Studies, University of Sheffield, S10 2TN, UK.
}

\begin{abstract}
In this paper a numerical analysis procedure which employs a sub-structuring technique together with selective node re-numbering, is described as a way of efficiently modelling the response of buildings to fires which are restricted to internal compartments. In this procedure user-defined cool regions of the building model are substructured and condensed into a linear "super-element", which has nodes connected to the non-linear sub-structures located within and in the immediate vicinity of the fire zone. The procedure has been incorporated into the non-linear program Vulcan which has been developed to model the structural response of loaded structures to fire attack, and two full-scale fire tests have been modelled to examine the computational efficiency of the method. The method makes it much easier than previously to investigate the influence of the surrounding cool structure on the behaviour of elements within the fire compartment, and its efficacy has been investigated for these two tests.
\end{abstract}

Keywords: Super-element; Sub-structuring; Re-numbering; Structural fire behaviour; Finite element analysis.

\section{INTRODUCTION}

The performance of structural elements exposed to fire is usually described in terms of their fire resistance, which is the period of time during exposure to fire at which "failure", according to a criterion usually based on deflection, occurs. Currently, this fire resistance is expressed only in relation to isolated element behaviour as determined by standard fire tests using a time-temperature curve given in ISO834 [1] and reproduced in most countries' codes of practice for fire testing. Predicting the behaviour of elements within a building in a real fire from ISO834 fire tests on isolated elements involves a clear and considerable simplification much greater than that which is made routinely in ambient-temperature design analysis. An important way in which the behaviour of elements in buildings differs from that of similar elements in these furnace tests derives from the very different boundary conditions which are imposed in the two situations. In a real building structural elements form part of a continuous assembly, and building fires often remain localised, with the fire-affected structure within a fire compartment being subject to significant restraint from the cooler areas surrounding it. The real behaviour of these structural elements, which is affected by the interaction of thermal expansion, material degradation and this boundary restraint, can therefore be totally different from that indicated by standard furnace tests. In 1995-96, six largescale fire tests were carried out on a composite steel-concrete building at the BRE Fire Research Laboratory at Cardington, in which the observed structural response supported this viewpoint.

Because such full-scale fire tests are extremely expensive, the development of analytical methods that can predict the behaviour of building structures when subjected to fire conditions is becoming increasingly important. In recent years a computer program Vulcan [2-8], has been developed at the University of Sheffield for three-dimensional analysis of the structural behaviour of composite and steel-framed buildings in fire. The program is based on a 3-D non-linear finite element procedure in which composite steel-framed buildings are modelled as an assembly of beam-column, spring, shear connector and slab elements. The beam-column line elements are three-noded, and their cross-section is divided into a number of segments to allow consideration of non-linear variation of temperature, stress and strain through the cross-section. A two-noded spring element of zero length is used to model the characteristics of steel member connections. In order to model partial interaction of the steel beam and the concrete slab in composite construction a shear 
connector elements has been developed to link slab and beam elements. The slabs are modelled using a nine-noded layered flat-shell element based on Mindlin-Reissner theory, in which each layer can have different temperature and material properties.

Modelling the structural behaviour of buildings in fire is inherently rather complex, because nonlinear structural analysis needs to be performed over the time-period of a given fire, during which element temperatures vary across the sections of members and slabs and also with location in the structure relative to the fire source. The materials of construction (steel and concrete of various grades) are subject to two dominant effects which depend on temperature; thermal straining and degradation of constitutive relationships. Material properties are non-linear, and it is necessary also to analyse the structural response up to much higher deflections than would be necessary at ambient temperature. Analyses can therefore be very expensive in computing time, especially when modelling large-scale problems. For example, for modelling a full-scale fire test [9] in a single corner bay of a composite building frame more than 10 hours' processing time was necessary on a 2.6GHz Pentium 4 personal computer. The modelling in that case used 226 elements (152 beamcolumn and 74 slab elements with 10 layers) with 369 nodes. For larger models with over 500 nodes run-times of the order of 20-30 hours are fairly usual. This has made the need to improve the computational efficiency of Vulcan a major issue of the program's development.

Fortunately, the design of buildings is influenced by fire safety legislation so that fires are often contained by internal fireproof compartmentation and remain localised. The influence on the behaviour of cool structure adjacent to the fire compartment is very important, because of the effects of continuity of structure into a much stiffer region, and also because of the restraint which is provided to thermal expansion of heated elements. It is therefore necessary to include a region of the surrounding cool structure in the modelling in order to represent more realistically the conditions affecting the fire compartment.

In fire conditions it is usual to assume that the loading applied generally to the structure is at a level well below that which would cause ambient-temperature yield to occur, and it is therefore reasonable to assume that, even during the fire, the adjacent cool structure remains linearly elastic, apart from some areas which are very close to the fire compartment. This is confirmed by observations from both test results and numerical studies. The objective of the present development was to take advantage of this observation in increasing the program's computational efficiency. The procedures for sub-structuring and static condensation in linear structural analysis are now well known [10-13], but little work has been done in extending the sub-structuring technique to non-linear analysis of the behaviour of buildings in fire. This paper describes the use of an appropriate procedure for using the sub-structuring technique, together with a re-numbering algorithm for more efficient modelling of this type. User-defined cool regions of the structures are sub-structured and condensed as a linear super-element, which has nodes connected to the nonlinear meshed sub-structure representing the fire compartment and a cool border zone. The procedure has been incorporated into Vulcan and some examples will be shown of the increased computational efficiency which is achieved.

\section{BUILDING A SUPER-ELEMENT}

In this paper a user-defined region of the finite element mesh, which includes only unheated elements, is assumed as a linear-elastic sub-structure (see Figure 1). For this region the relationship between the stiffness matrix $\mathbf{K}_{\mathbf{s b}}$, the corresponding displacement vector $\mathbf{U}_{\mathbf{s b}}$ and the load vector $\mathbf{R}_{\mathbf{s b}}$ is expressed as

$$
\mathbf{K}_{\mathrm{sb}} \mathbf{U}_{\mathrm{sb}}=\mathbf{R}_{\mathrm{sb}}
$$


In order to establish a super-element the static condensation procedure is used. Eq. (1) is partitioned, as in [14], into the form

$$
\left[\begin{array}{ll}
\mathbf{K}_{\mathrm{aa}} & \mathbf{K}_{\mathrm{ac}} \\
\mathbf{K}_{\mathrm{ca}} & \mathbf{K}_{\mathrm{cc}}
\end{array}\right]\left[\begin{array}{l}
\mathbf{U}_{\mathbf{a}} \\
\mathbf{U}_{\mathbf{c}}
\end{array}\right]=\left[\begin{array}{l}
\mathbf{R}_{\mathbf{a}} \\
\mathbf{R}_{\mathbf{c}}
\end{array}\right]
$$

in which $\mathbf{U}_{\mathbf{a}}$ and $\mathbf{U}_{\mathbf{c}}$ are respectively the vectors of the degrees of freedom to be retained (the boundary nodes between the super-element and the non-linear mesh) and those which are to be condensed out (the other nodes of the super-element).

The matrix equation for the nodes to be condensed out can be expressed from Eq. (2) as:

$$
\mathbf{U}_{\mathrm{c}}=\mathbf{K}_{\mathrm{cc}}^{-1}\left(\mathbf{R}_{\mathrm{c}}-\mathbf{K}_{\mathrm{ca}} \mathbf{U}_{\mathrm{a}}\right)
$$

The relationship in Eq. (3) is used to substitute for $\mathbf{U}_{\mathbf{c}}$ into the boundary node equations in Eq. (2) to obtain the condensed equations

$$
\left(\mathbf{K}_{\mathrm{aa}}-\mathbf{K}_{\mathrm{ac}} \mathbf{K}_{\mathrm{cc}}^{-1} \mathbf{K}_{\mathrm{ca}}\right) \mathbf{U}_{\mathrm{a}}=\mathbf{R}_{\mathrm{a}}-\mathbf{K}_{\mathrm{ac}} \mathbf{K}_{\mathrm{cc}}^{-1} \mathbf{R}_{\mathrm{c}}
$$

If we use

$$
\mathbf{K}_{\text {super }}=\mathbf{K}_{\mathrm{aa}}-\mathbf{K}_{\mathrm{ac}} \mathbf{K}_{\mathrm{cc}}^{-1} \mathbf{K}_{\mathrm{ca}}
$$

and

$$
\mathbf{R}_{\text {super }}=\mathbf{R}_{\mathrm{a}}-\mathbf{K}_{\mathrm{ac}} \mathbf{K}_{\mathrm{cc}}^{-1} \mathbf{R}_{\mathrm{c}}
$$

Eq. (4) becomes

$$
\mathbf{K}_{\text {super }} \mathbf{U}_{\mathbf{a}}=\mathbf{R}_{\text {super }}
$$

in which $\mathbf{K}_{\text {super }}$ and $\mathbf{R}_{\text {super }}$ are respectively the stiffness matrix and load vector of the super-element. From Eq. (7) it can be seen that the degrees of freedom related to the super-element are the displacements $\mathbf{U}_{\mathbf{a}}$ which are to be retained. Since Eq. (1) represents the relationship between the stiffness matrix $\mathbf{K}_{\mathbf{s b}}$, the corresponding displacement vector $\mathbf{U}_{\mathbf{s b}}$ and the load vector $\mathbf{R}_{\mathbf{s b}}$ for a linear-elastic sub-structure, $\mathbf{K}_{\mathbf{s b}}$ is unchanged during non-linear analysis. Hence, the stiffness matrix of the super-element $\mathbf{K}_{\text {super }}$ is constant.

A frontal solution method [15] is used during the condensation procedure for the super-element, to enable the program to model large-scale structures without difficulty.

\section{MODELLING OF STRUCTURES IN FIRE}

When the stiffness matrix for the super-element has been constructed it is used as a boundary element connected to the sub-structure which is modelled using normal meshing of non-linear elements. During the subsequent non-linear analysis the stiffness matrix of the super-element $\mathbf{K}_{\text {super }}$ remains constant. This non-linear solution procedure determines the deformations $\mathbf{U}_{\mathbf{n l}}$ of the nodes under equivalent external loads $\mathbf{R}_{\mathbf{n l}}$, which are assumed to be applied the nodes and are usually constant in the fire condition, whilst the temperature increases. In this procedure a number of parameters are temperature-dependent. The basic equilibrium equation at any load or temperature step is

$$
\mathbf{R}_{\mathbf{n l}}-\mathbf{Q}_{\mathbf{n l}}=\mathbf{0}
$$

where $\mathbf{Q}_{\mathbf{n l}}$ is the vector of internal nodal forces.

The stiffness matrix $\mathbf{K}_{\mathbf{n l}}$, the internal force vector $\mathbf{Q}_{\mathbf{n l}}$ and the equivalent external loads $\mathbf{R}_{\mathbf{n l}}$ for the structure being analysed are expressed as 


$$
\begin{aligned}
& \mathbf{K}_{\mathrm{nl}}=\sum_{\mathrm{j}=1}^{\mathrm{n}} \mathbf{K}_{\mathbf{j}}+\mathbf{K}_{\text {super }} \\
& \mathbf{Q}_{\mathrm{nl}}=\sum_{\mathrm{j}=1}^{\mathbf{n}} \mathbf{Q}_{\mathbf{j}}+\mathbf{Q}_{\text {super }} \\
& \mathbf{R}_{\mathrm{nl}}=\sum_{\mathbf{j}=1}^{\mathrm{n}} \mathbf{R}_{\mathbf{j}}+\mathbf{R}_{\text {super }}
\end{aligned}
$$

in which $\mathbf{K}_{\mathbf{j}}, \mathbf{Q}_{\mathbf{j}}, \mathbf{R}_{\mathbf{j}}$ and $\mathrm{n}$ are respectively the element stiffness matrix, internal force vector and external load vector, and $\mathrm{n}$ is the total number of elements of the non-linear sub-structure. $\mathbf{Q}_{\text {super }}$ is the internal force vector of the super-element. Because the super-element is linearly elastic, $\mathbf{Q}_{\text {super }}$ can be calculated using

$$
\mathbf{Q}_{\text {super }}=\mathbf{K}_{\text {super }} \mathbf{U}_{\text {super }}
$$

where $\mathbf{U}_{\text {super }}$ is the nodal displacement vector of the super-element and $\mathbf{U}_{\text {super }}=\mathbf{U}_{\mathbf{a}}$.

The stiffness matrix of the super-element $\mathbf{K}_{\text {super }}$ is symmetric and banded. After its skyline has been determined only the elements below the upper skyline, including the diagonal elements, are stored in a one-dimensional array and are used to form $\mathbf{K}_{\mathbf{n l}}$ and $\mathbf{Q}_{\text {super }}$.

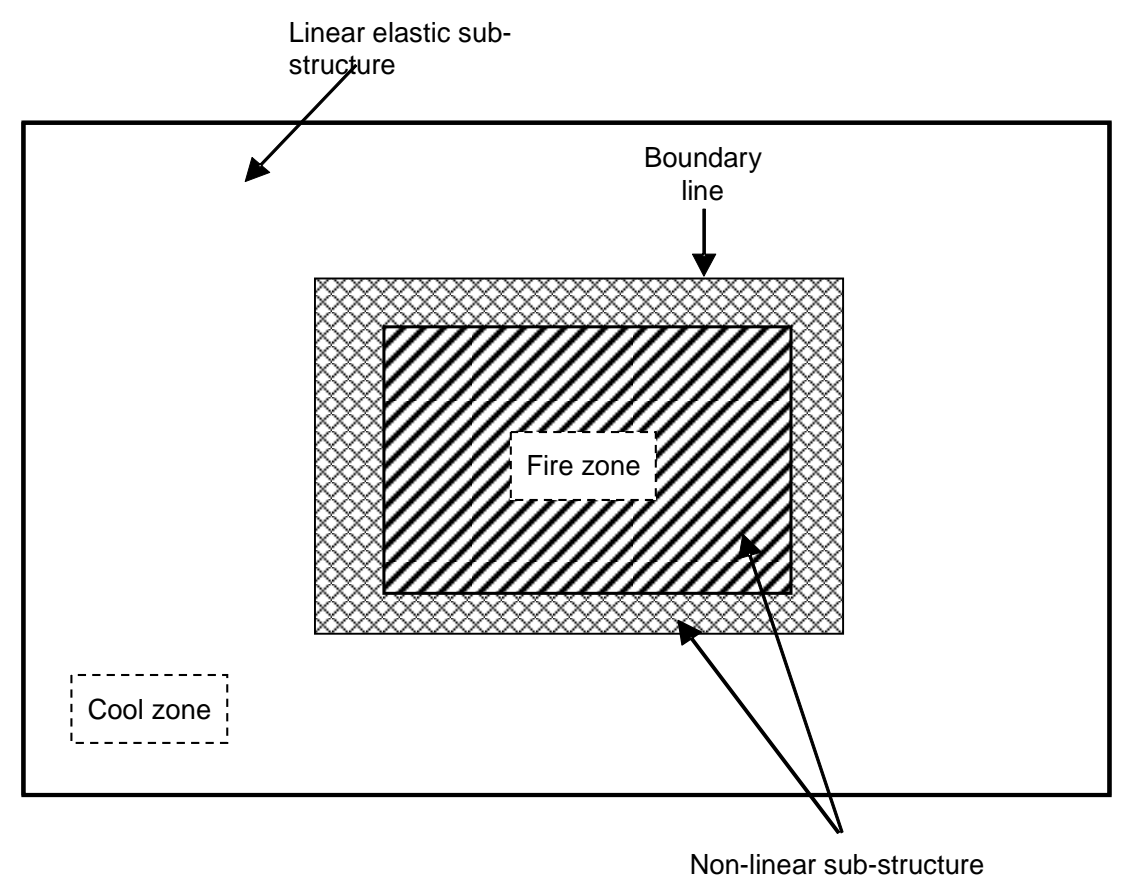

Figure 1. Sub-structuring scheme for structural analysis in fire.

For composite steel-framed buildings in fire, Eq. (8) is highly non-linear, and the Newton-Raphson iteration procedure is employed. The total time period or temperature range for which the response of the structure is to be traced is divided into a number of steps. It is assumed that changes in the loads or temperatures occur only at the beginning or end of a step. During any step the external loads, and the temperatures in the layers of slab elements and the segments of beam-column elements, are assumed to remain constant. During this incremental solution process the stiffness matrix of the super-element $\mathbf{K}_{\text {super }}$ remains constant. The total number of nodes and elements for which non-linear analysis has to be carried out is reduced to those within the selected region, whilst retaining the effect of either the whole or a large part of the structure which is not directly involved in the fire. 


\section{RE-NUMBERING PROCEDURE}

An undesirable effect of the condensation process is that it creates an element with a very large number of nodes, whose stiffness matrix is very highly populated and therefore has a bandwidth very close to the maximum possible for its final degrees of freedom. The node numbering of the remaining sub-structure for non-linear analysis may become very badly conditioned when it is reassembled with the super-element. This can cause a very much broader bandwidth of the structural stiffness matrix than would occur if the problem were solved without sub-structuring. In general solution time is related to the square of the bandwidth, while it is only linearly related to the dimension of the stiffness matrix. Thus the considerable decrease in the number of nodes considered due to condensation may be offset by the increase in bandwidth [10], and may in consequence produce no improvement in processing times. It is therefore necessary to re-number the remaining sub-structure, including the nodes connecting the super-element to the non-linear region, in order to reduce the bandwidth to a more optimal level.

A re-numbering algorithm proposed by Burgess and Lai [16] has been adopted in this paper. There are seven stages in this re-numbering procedure:

1. The nodes and elements of the remaining sub-structure for non-linear analysis are listed using a continuous number sequence, removing the gaps created by the creation of the super-element. A mapping array is created to relate this numbering to the original scheme which has been used by the creator of the data file.

2. A nodal inter-connectivity matrix is built up based on this new node numbering.

3. Based on the inter-connectivity matrix a starting node for re-numbering is chosen using the method proposed by Gibbs, Poole and Stockmeyer [17].

4. Starting from this starting node and working according to the stiffness connectivities, the original node structure is converted to a level structure of nodes.

5. A second pass is made across the level structure, and an attempt is made to 'smooth' the level heights to a more uniform average height before re-numbering takes place [16].

6. The modified node level structure is then re-numbered using the well-known method based on the work of Cuthill and McKee [18] and Cheng [19].

7. After re-numbering the mapping array is updated. The structural information relating to the original numbering system is re-sequenced in the new numbering system and is then ready for starting non-linear analysis. The details of the stages from (3) to (5) can be found in Burgess and Lai [16].

\section{NUMERICAL EXAMPLES}

The procedures described above for creating a super-element and re-numbering the residual substructure have now been incorporated within Vulcan, and have been tested in three-dimensional modelling of the structural behaviour of composite steel-framed buildings in fire. The numerical procedure is summarised in Figure 2. The program is now capable of being run in three ways: (1) using the original procedure without any sub-structuring or re-numbering; (2) using the original procedure after re-numbering; (3) using the new procedure with a super-element and subsequent renumbering. In order to demonstrate the key effects of the new procedures, two of the six full-scale compartment fire tests which were carried out in 1995-96 in an 8-storey composite frame structure at the BRE laboratory at Cardington are modelled here. The Cardington building was constructed during 1994, to resemble a modern city-centre medium-rise office development typical of current UK practice. The influence of the modelling of the cool structure adjacent to fire compartments on the behaviour of the structure within it is investigated. The studies were run on a Pentium 4, 2.6GHz personal computer with 1.0Gb of RAM. 


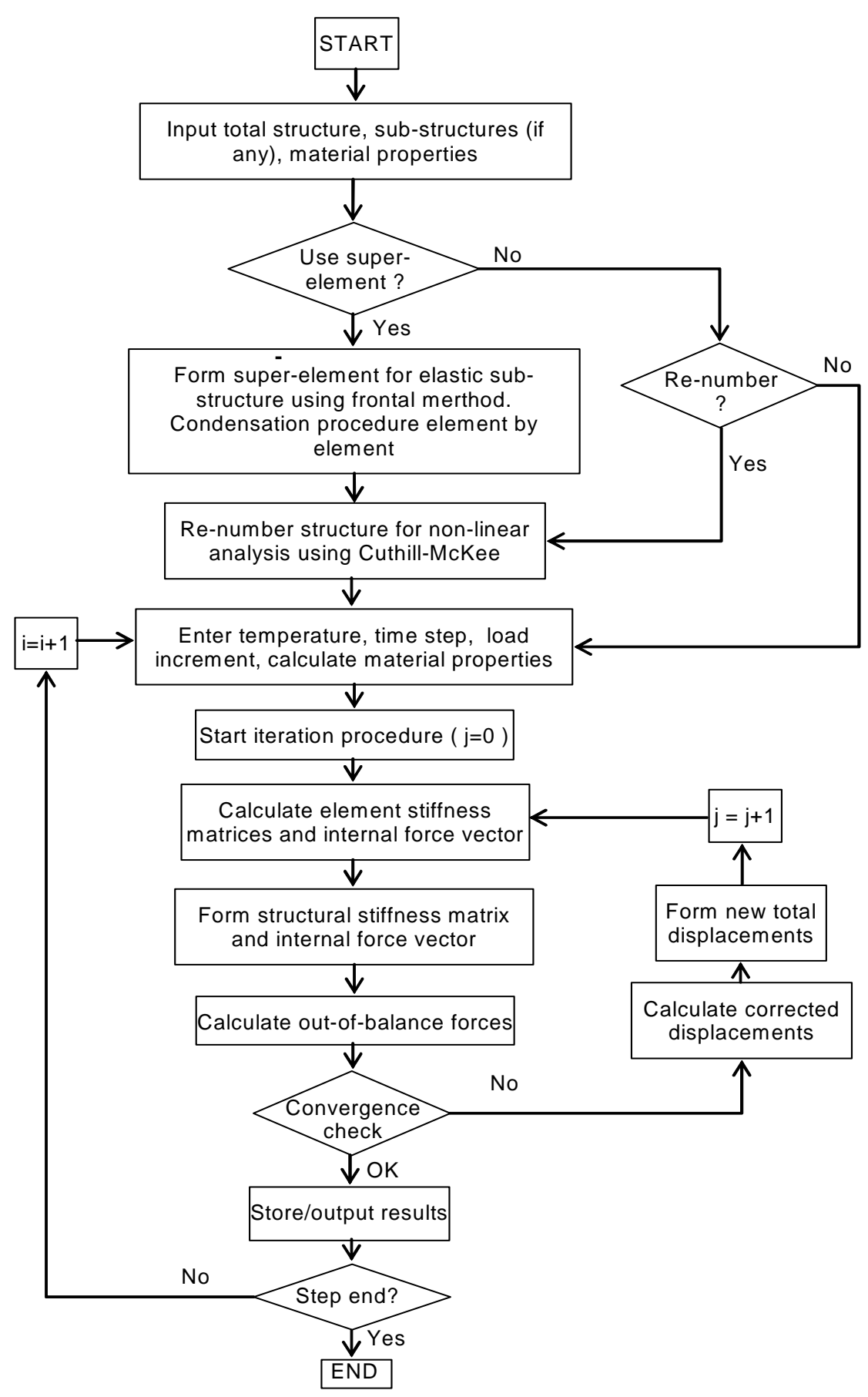

Figure 2. A flowchart of the program Vulcan including the sub-structuring scheme.

\section{MODELLING OF THE “RESTRAINED BEAM TEST”}

The "Restrained Beam Test" was the first, and the smallest, of the fire tests carried out on the test building. It was conducted [20, 21] by British Steel plc in January 1995, and involved heating a single secondary beam and an area of the surrounding slab on the seventh floor. The steel member tested consisted of a 305x165UB40 section spanning between columns D2 and E2, and was heated using a specially constructed gas-fired furnace over the central $8 \mathrm{~m}$ of its $9 \mathrm{~m}$ length. The location of the test is shown in Figure 3. The sub-frame which has been modelled, including a region of the surrounding cool structure, is also shown in Figure 3, with a more detailed representation, including the finite element mesh layout adopted, in Figure 4. 


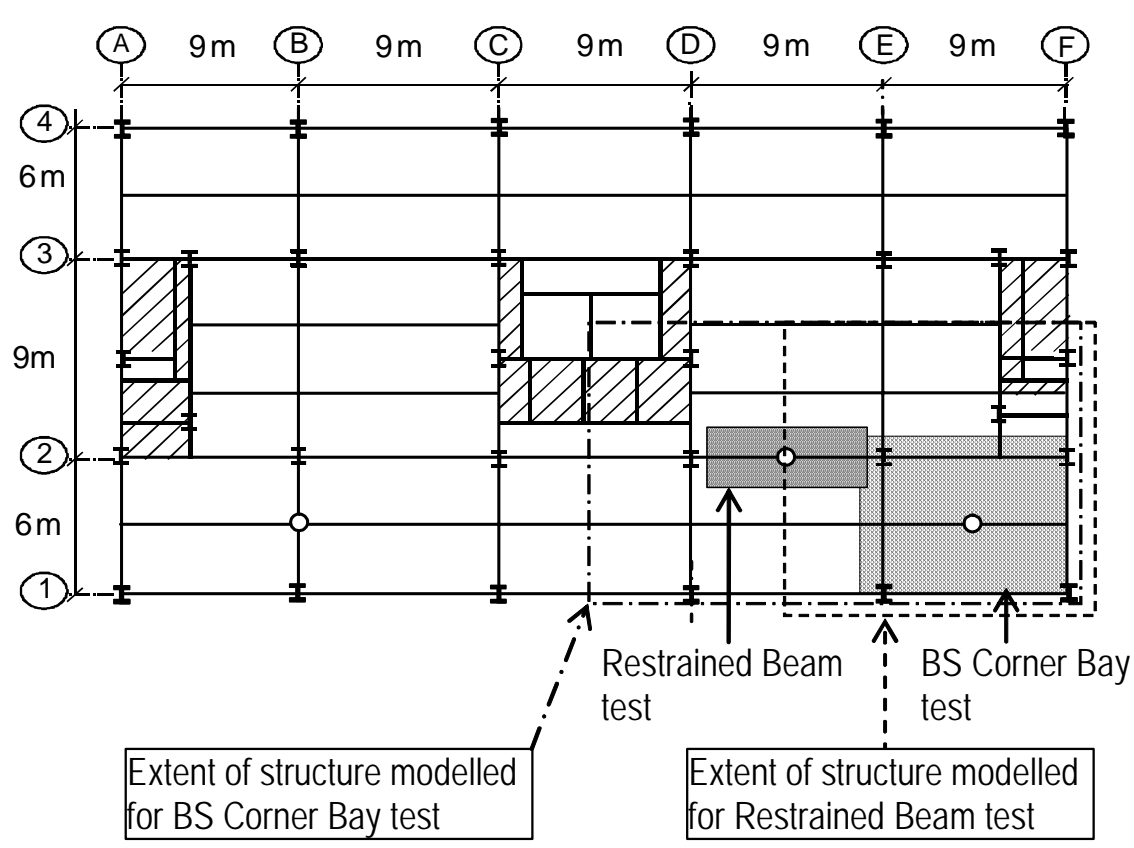

Figure 3. Locations of Restrained Beam Test and British Steel Corner Bay Test in the Cardington composite test frame.

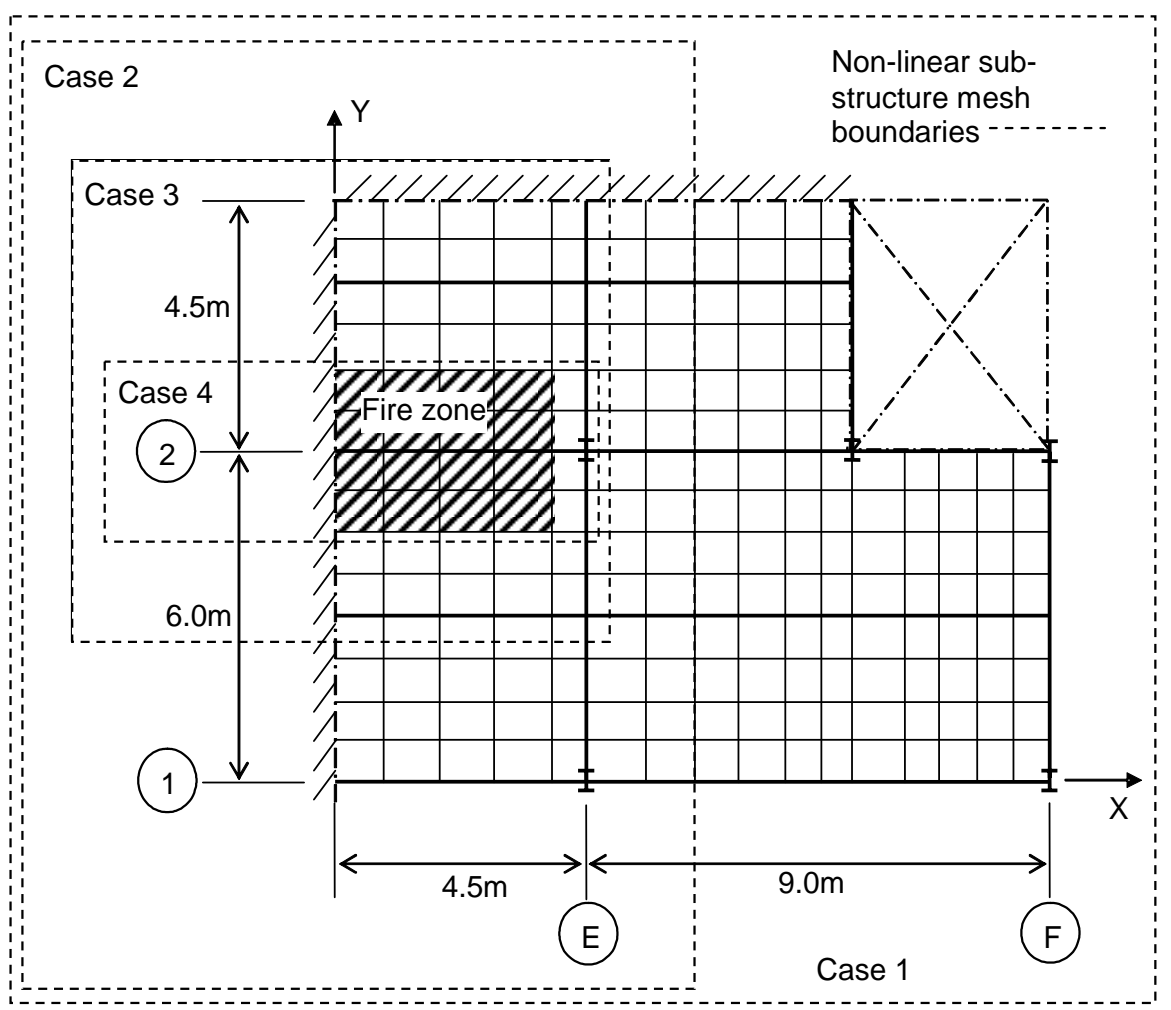

Figure 4. Finite element layout adopted in the analysis of the Restrained Beam Test, together with the boundaries of the non-linear sub-structures for the four cases studied.

The ambient-temperature material properties used in the modelling were as follows:

- The yield strength of steel was assumed as 308MPa for Grade 43 steel (S275) and 390MPa for Grade 50 (S355), based on coupon test results provided by the supplier.

- The yield strength of reinforcing steel was assumed to be $460 \mathrm{MPa}$.

- The elastic modulus of steel was $210 \mathrm{kN} / \mathrm{mm}^{2}$.

- The average concrete compressive strength was 35MPa. 
A uniform floor load of $5.48 \mathrm{kN} / \mathrm{m}^{2}$ was applied using sandbags. The temperature distributions in the steel beam and the slab were taken as the average of the recorded temperature distributions across the cross-section of the beam and the thickness of the slab at any stage in the test. The test was terminated due to a failure of some instrumentation when the steel beam temperature was above $800^{\circ} \mathrm{C}$, and no structural failure was seen although large deflections were achieved.

In this example four cases, all of which are illustrated in Figure 4, have been analysed. In Case 1 (normal modelling) the whole sub-frame was modelled as a non-linear sub-structure, but different extents of non-linear sub-structure were used for Cases 2 to 4 . Their basic statistics, including runtimes, are given in Table 1. In the selection of super-element configurations here only the intuitively sensible arrangements shown in Figure 4 have been considered. The ten-fold time saving between Cases 1 and 2 is achieved by using the whole developed procedure. The influence of re-numbering within this process (considered separately from the creation of a super-element) can be gauged from a re-run of Case 1 after re-numbering. The run-time in this case was 201 minutes, compared with 280 for the original numbering, a significant but unspectacular saving. The presence of columns above and below the floor structure is capable of causing very large, sparsely populated bandwidths without re-numbering, and the height of skyline within the total structural stiffness matrix is increased dramatically.

Table 1. Cardington Restrained Beam test: performance using different super-elements.

\begin{tabular}{|l|c|c|c|c|c|c|}
\hline \multirow{2}{*}{ Case } & \multicolumn{2}{|c|}{ Elements } & \multicolumn{2}{c|}{ Nodes } & \multicolumn{2}{c|}{ Run-time } \\
& $\begin{array}{c}\text { Non-linear } \\
\text { sub-frame }\end{array}$ & $\begin{array}{c}\text { Super- } \\
\text { element }\end{array}$ & $\begin{array}{c}\text { Non-linear } \\
\text { sub-frame }\end{array}$ & $\begin{array}{c}\text { Super- } \\
\text { element }\end{array}$ & & (\%) \\
\hline 1 (normal) & 208 & 0 & 343 & 0 & 280 & 100.0 \\
\hline 2 & 116 & 92 & 214 & 129 & 25.3 & 9.0 \\
\hline 3 & 65 & 143 & 135 & 208 & 18.8 & 6.7 \\
\hline 4 & 20 & 188 & 77 & 266 & 4.3 & 1.5 \\
\hline 1 (re-numbered) & 208 & 0 & 343 & 0 & 201 & 71.8 \\
\hline
\end{tabular}

It is necessary to check that accuracy is being maintained in the prediction of overall response, and also that the localised behaviour in the zone of interest is not changed radically by connection to the super-element. In order to examine the effect on overall accuracy of the modelling the mid-span deflections of the heated beam are plotted in Figure 5 for all cases against the temperature of the bottom flange of the beam, together with the measured test results. It can be seen that Case 2 produces results almost identical to those from normal modelling (Case 1), which itself compares well with the test results. Case 3 involves some minor sacrifice of accuracy in the final range of test temperatures; this might be anticipated to increase if the temperatures were increased further. Case 4, in which only the tested beam and the concrete slab within the furnace width are contained within the non-linear sub-frame, shows the effect of eliminating failure in the immediately adjacent zones from the analysis. Below a beam lower flange temperature of $200^{\circ} \mathrm{C}$ the deflections are almost identical to those given by the other modelling, whereas above $400^{\circ} \mathrm{C}$, when

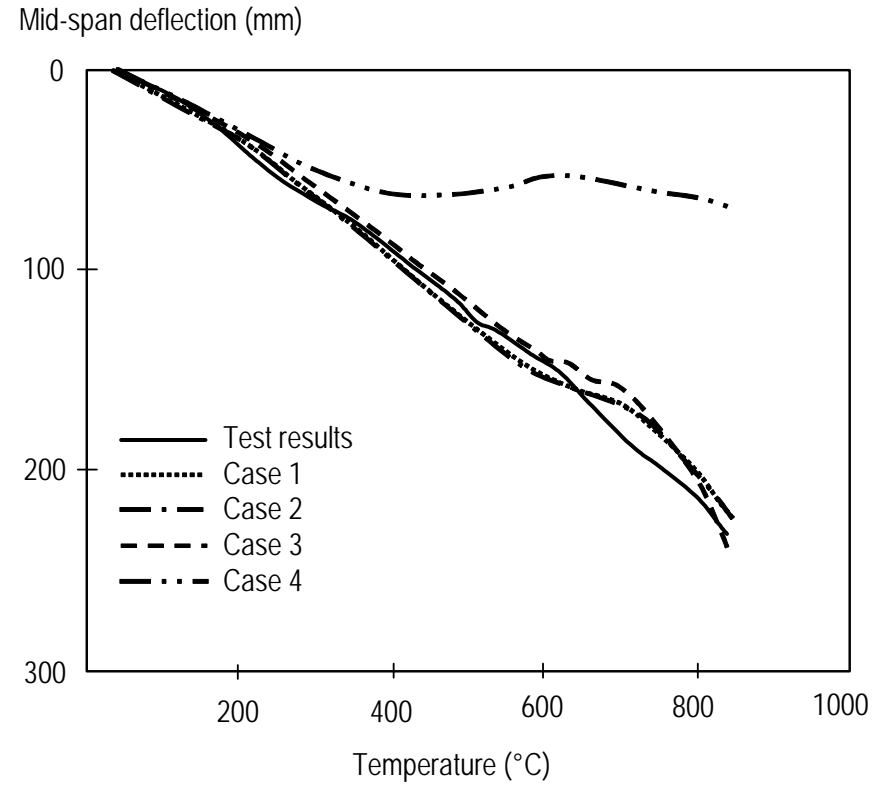

Figure 5. Comparison of predictions with measured mid-span deflections for the different non-linear sub-structures analysed in the Restrained Beam Test. 
the steel loses strength rapidly, the deflections cease as the heated zone effectively re-distributes its load to the surrounding elastic material.

In order to examine local failure behaviour the slab cracking patterns shown in the normal modelling (Case 1) and the most moderate of the other cases (Case 2) are shown at ambient temperature and at the final stage, when the beam lower flange is at $835^{\circ} \mathrm{C}$. Nine Gauss integration points are used for each slab element, and at these positions the development of cracking or crushing in the concrete can be detected in the non-linear sub-structure. Figures 6(a)-(d) and Figures 7(a)-(d) show schematically the cracking and crushing patterns at the top and bottom of the floor slab at ambient temperature and a beam lower flange temperature of $835^{\circ} \mathrm{C}$ for Cases 1 and 2 respectively. It can be seen that there is some cracking of the concrete slabs at ambient temperature, which of course includes both the test area and the surrounding cool structure. At the final temperature there is considerably more cracking, and some small zones of concrete crushing. It is interesting to observe that the failure patterns of the concrete slabs within the non-linear substructures for both cases are very similar.

Figures 8(a)-(d) show the vector plot of distribution of principal membrane tractions (forces per unit width of slab) at the Gauss points of the slab elements, both at ambient temperature and at a beam lower flange temperature of $835^{\circ} \mathrm{C}$ for Cases 1 and 2 respectively. In the figures the lengths of the vectors are proportional to their magnitudes; thin vector lines denote tension and thick lines denote compression. It can be seen that at ambient temperature the slabs above the secondary and primary beams act very much in line with the normal engineer's assumption for the flanges of composite beams, being in compression parallel to the beam. This reduces somewhat in the areas mid-way between parallel beams due to the well-known phenomenon of shear lag. In contrast, it can be seen that at high temperature (beam lower flange $835^{\circ} \mathrm{C}$ ) very high compressive tractions are formed in the slab surrounding the edges of the fire compartment, and within the fire compartment the compressive tractions gradually reduce from the edges into the central areas. It is evident that the distributions of membrane tractions of the concrete slabs within the non-linear substructures are very similar for both cases. This suggests that the behaviour of structure in the fire compartment is mainly influenced by its immediate surroundings, which can be included within the non-linear sub-structure, and that the use of a linear super-element outside this zone is justifiable.
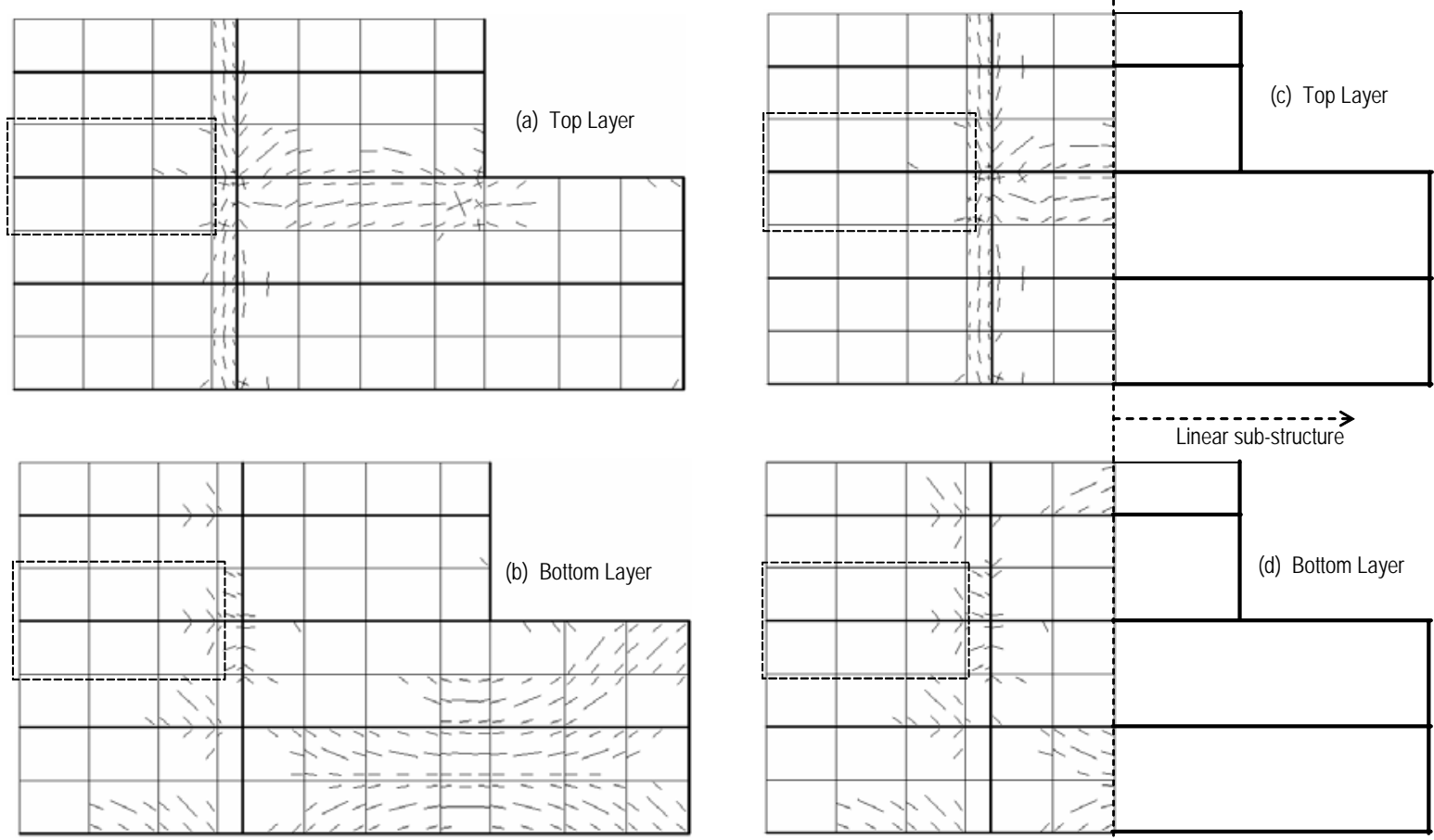

Figure 6. Predicted cracking patterns of top and bottom layers of floor slab at $20^{\circ} \mathrm{C}$ in the Restrained Beam Test for Case 1 (a, b) and Case 2 (c, d). 

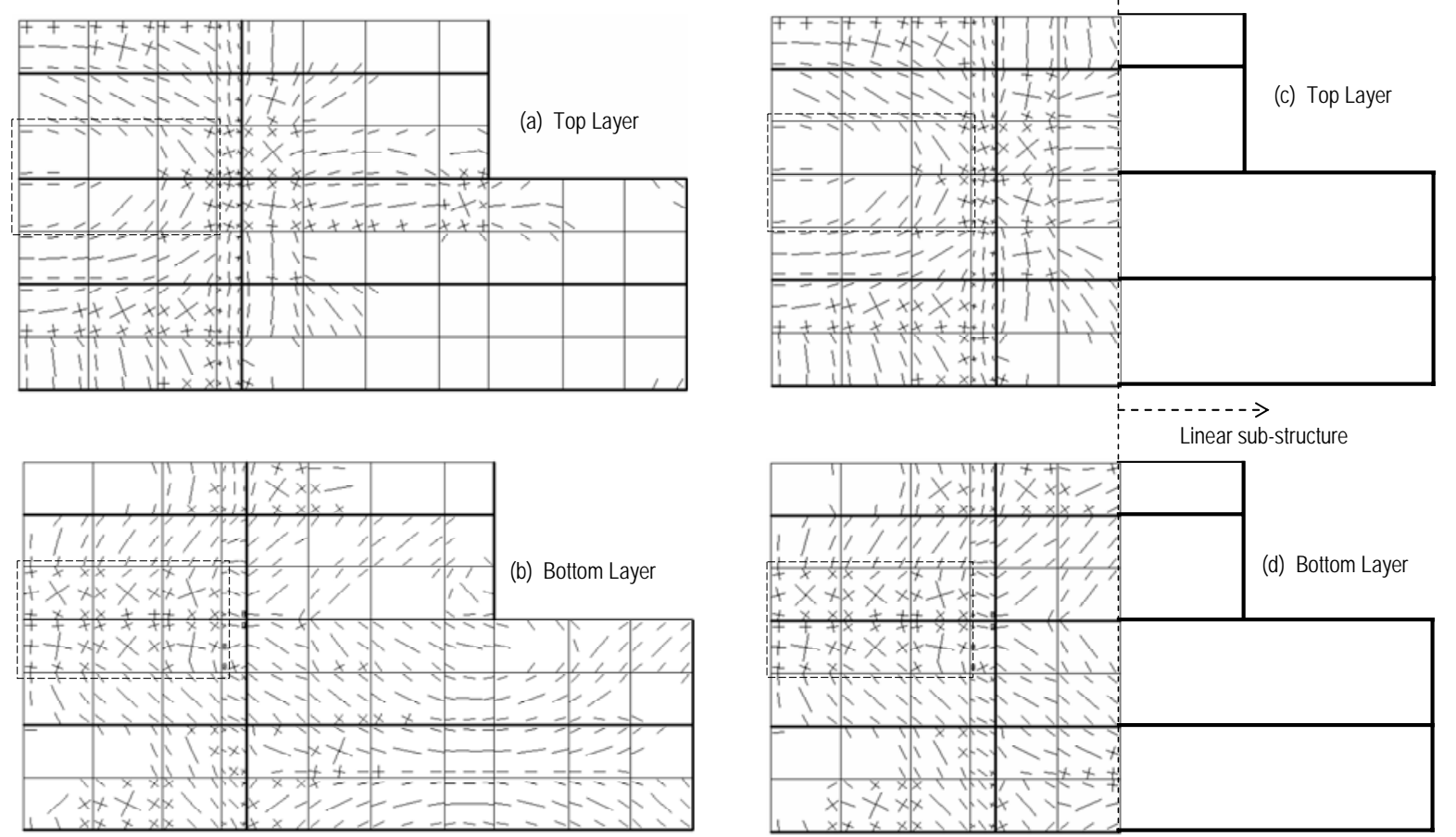

Figure 7. Predicted cracking patterns of top and bottom layers of floor slab at beam temperature $835^{\circ} \mathrm{C}$ in the Restrained Beam Test for Case 1 (a, b) and Case 2 (c, d).
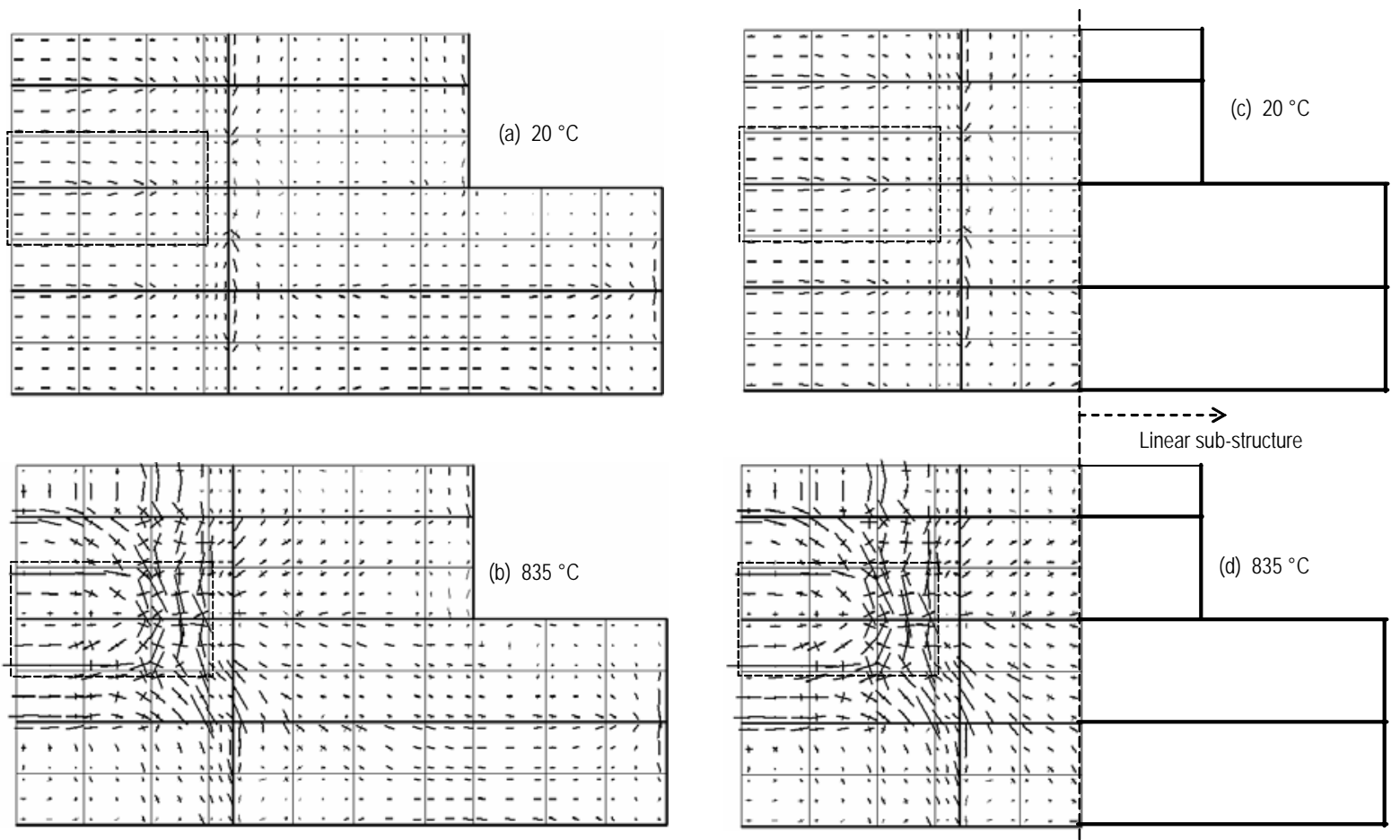

Figure 8. Predicted distribution of principal membrane tractions at $20^{\circ} \mathrm{C}$ and $835^{\circ} \mathrm{C}$ in the Restrained Beam Test for Case 1 (a, b) and Case 2 (c, d). (thick line=compression; thin line=tension).

Use of the super-element had the effect not only of reducing the total elements and nodes needed for the analysis but also of making the non-linear procedure more stable and of reducing the average number of iterations needed for each step. 


\section{MODELLING OF THE “BRITISH STEEL CORNER TEST”}

In July 1995 a fire test (Test 3 of the British Steel series) was carried out [22, 23] in a compartment of dimensions $9.98 \mathrm{~m} \times 7.57 \mathrm{~m}$ in a corner bay of the structure. The walls of the fire compartment, shown schematically in Figure 3, were constructed using lightweight concrete blockwork, the top of which was detached from the structure above so as to allow free deflection. The columns and building-edge beams were wrapped with ceramic fibre, but all other structural elements were left unprotected. The test used timber cribs giving an overall fire load of $45 \mathrm{~kg} / \mathrm{m}^{2}$ to produce a natural fire. During the fire test the maximum recorded atmosphere temperature in the compartment was $1028^{\circ} \mathrm{C}$, which occurred after 80 minutes. Steel temperatures and structural deflections were recorded at key locations and at required intervals throughout the test, providing information for comparison with analytical results. A description of the test, and comprehensive records of measured temperatures and deflections, are given in Refs. 22 and 23.

The test location, the extent of the structure incorporated within the numerical modelling, and the finite element mesh layout are shown in Figures 3 and 9. The ambient-temperature material properties are identical to those given for the Restrained Beam Test. The uniform floor load of $5.48 \mathrm{kN} / \mathrm{m}^{2}$ was again applied using sandbags. In order to rationalise the test temperature profiles of beams and columns (see Figure 9 for the beam positions) the following assumptions were made:

- $\quad$ Unprotected beams B1/2, B2, and BE have the same temperature distributions, in which the maximum temperatures of the bottom flange, web and top flange are $900^{\circ} \mathrm{C}, 860^{\circ} \mathrm{C}$, and $800^{\circ} \mathrm{C}$ respectively.

- Protected beams B1 and BF have the same temperature distributions, in which the maximum temperatures of the bottom flange, web and top flange were $250^{\circ} \mathrm{C}, 180^{\circ} \mathrm{C}$, and $110^{\circ} \mathrm{C}$ respectively.

- The cross-sections of all protected columns have uniform temperature distributions with a maximum temperature of $160^{\circ} \mathrm{C}$.

- $\quad$ The average test temperature distribution through the thickness of the concrete slab was used at each stage, with the maximum temperatures of the bottom and top layers at $360^{\circ} \mathrm{C}$ and $70^{\circ} \mathrm{C}$ respectively. In the following text the temperature quoted in all figures refers to the temperature of the bottom flange of the hottest beams.

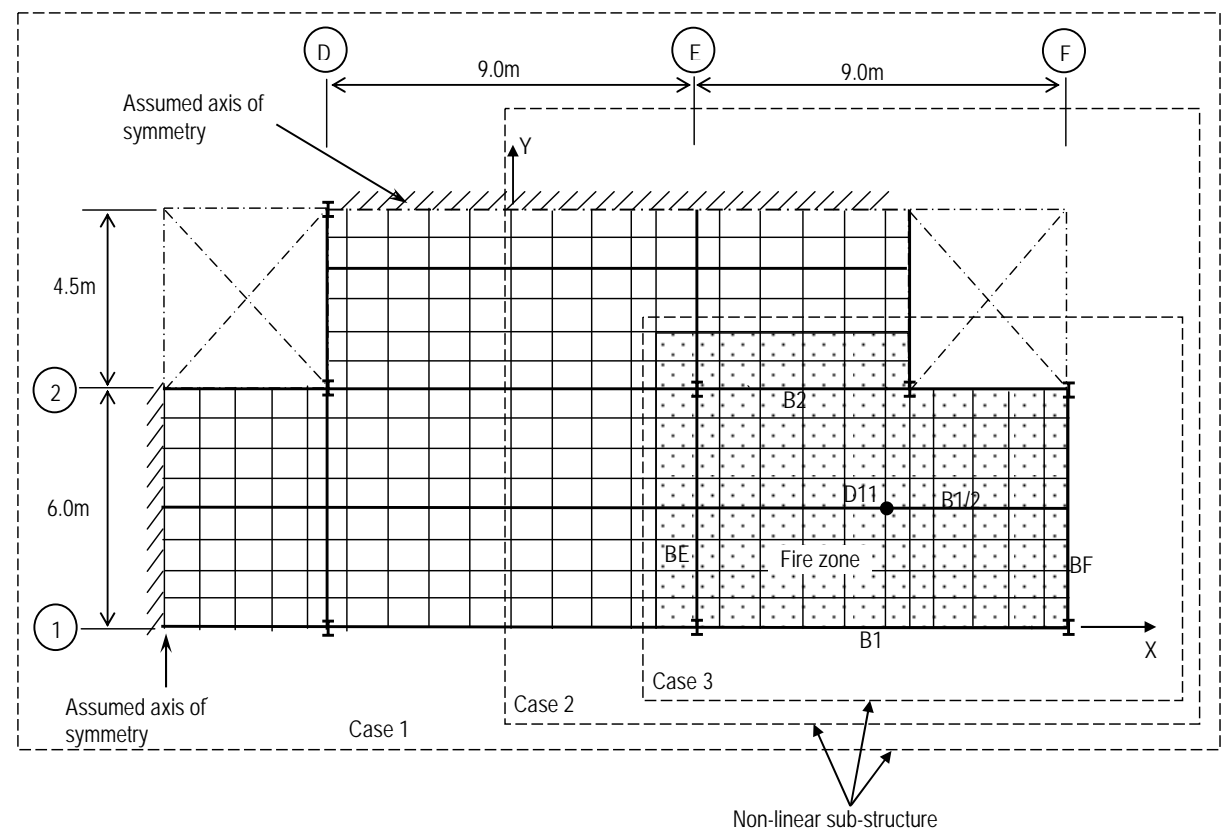

Figure 9. Finite element layout adopted in the analysis for British Steel Corner Test, together with the locations of non-linear sub-structures for the three cases studied. 
In this example three cases, which are illustrated in Figure 9, have been analysed. In Case 1 (normal modelling) the whole sub-frame was modelled as a non-linear sub-structure, while different sizes of non-linear sub-structure were employed for Cases 2 and 3. Their basic statistics, including run-times, are given in Table 2.

Table 2. Cardington British Steel Corner Test: performance using different super-elements.

\begin{tabular}{|l|c|c|c|c|c|c|}
\hline \multirow{2}{*}{ Case } & \multicolumn{2}{|c|}{ Elements } & \multicolumn{2}{c|}{ Nodes } & \multicolumn{2}{c|}{ Run-time } \\
& $\begin{array}{c}\text { Non-linear } \\
\text { sub-frame }\end{array}$ & $\begin{array}{c}\text { Super- } \\
\text { element }\end{array}$ & $\begin{array}{c}\text { Non-linear } \\
\text { sub-frame }\end{array}$ & $\begin{array}{c}\text { Super- } \\
\text { element }\end{array}$ & & (\%) \\
\hline 1 (normal) & 334 & 0 & 532 & 0 & 1800 & 100.0 \\
\hline 2 & 226 & 108 & 387 & 145 & 236 & 13.1 \\
\hline 3 & 134 & 200 & 250 & 282 & 212 & 11.7 \\
\hline 1 (re-numbered) & 334 & 0 & 532 & 0 & 851 & 47.0 \\
\hline
\end{tabular}

The deflections at position D11, which is the mid-span of heated beam B1/2 are plotted in Figure 10 against the temperature of the bottom flange of this beam for all three cases, together with the measured test result. It can be seen that the three modelling cases produced almost identical results, the only small difference appearing for temperatures above $800^{\circ} \mathrm{C}$. There was a significant saving of run-time for Case 2, at $13.1 \%$ of the time for Case 1 (normal modelling). For Case 3 a further saving was achieved, at only $11.7 \%$ of the time for Case 1 , but with a sacrifice of some accuracy in the analysis. The normal modelling, Case 1, was re-run after simply re-numbering the mesh, and the run-time in this case was 851 minutes, or $47 \%$ of that for Case 1 .

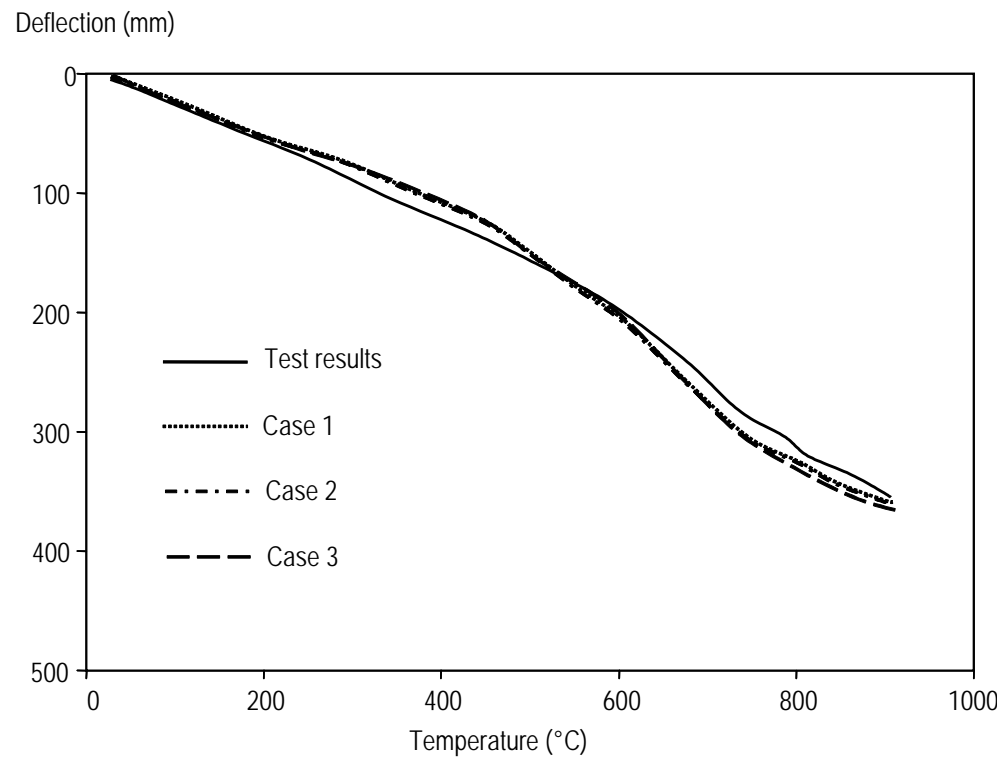

Figure 10. Comparison of predictions with measured deflections at position D11 for different non-linear sub-structures analysed for the British Steel Corner Test.

Once again the cracking and crushing patterns of the top and bottom layers of the floor slab, at ambient temperature and at a beam lower flange temperature of $900^{\circ} \mathrm{C}$, are shown in Figures $11(\mathrm{a})$ (d) and Figures 12(a)-(d) for Cases 1 and 2 respectively. As for the Restrained Beam Test the failure patterns of the concrete slabs within the non-linear sub-structures for both cases were very similar. Figures 13(a)-(d) show the distributions of principal membrane tractions at ambient temperature and at a beam lower flange temperature of $900^{\circ} \mathrm{C}$ for Cases 1 and 2 respectively. The distribution of the two principal membrane tractions in the slab at a heated beam lower flange temperature of $900^{\circ} \mathrm{C}$ shows that the load-carrying mechanism has very visibly changed at this high-temperature stage of the structural action. It can be seen from Figure 10 that, when the temperatures of the steel beam were less than $700^{\circ} \mathrm{C}$ and the vertical deflections were less than 
$300 \mathrm{~mm}$, there was little influence of geometric non-linearity on the load-carrying mechanism. On further increase of temperature, when the steel beams had lost most of their strength, the loads above fire compartment were largely carried by the floor slab rather than by composite bending. In this corner test little in-plane restraint was capable of being provided by surrounding cool structure, and so the floor slabs within the corner bay need to be almost self-equilibrating in the horizontal plane. This means that the tensile membrane tractions within the central zone of the floor slab are balanced by the compression forces formed around the perimeter of the fire compartment. These are made possible by the presence of vertical support due to the protected beams, which forces the slab to deform in double curvature and thus to generate the membrane traction fields shown in Figures 13(b) and (d). The load-carrying capacity of the slabs was increased significantly due to this tensile membrane action, in which the anti-cracking reinforcement mesh is a key component. Once more the distributions of membrane tractions of the concrete slabs within the non-linear substructures for both cases are very similar.

(a) Top Layer

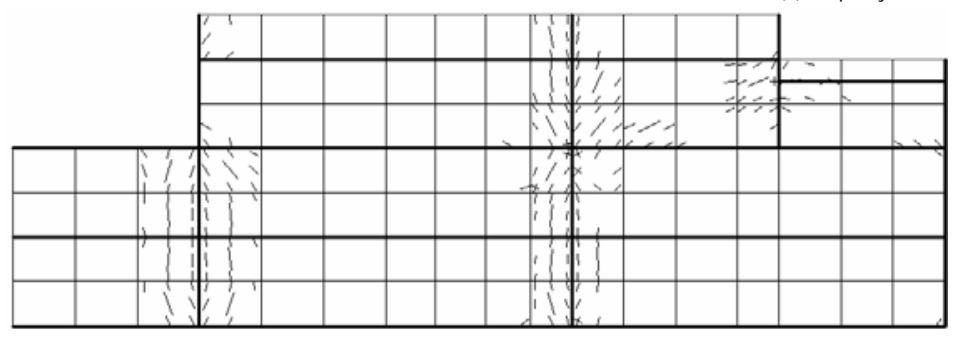

(b) Bottom Layer

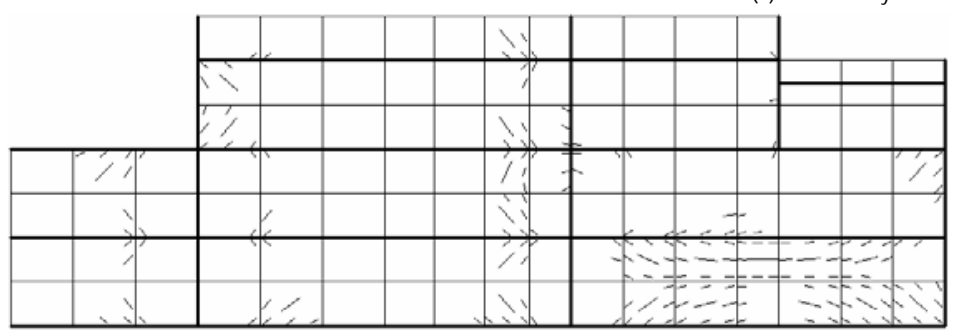

(c) Top Layer

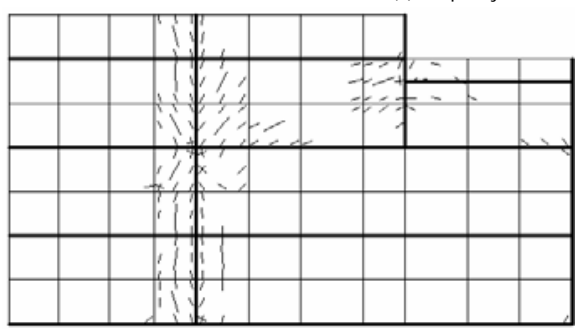

(d) Bottom Layer

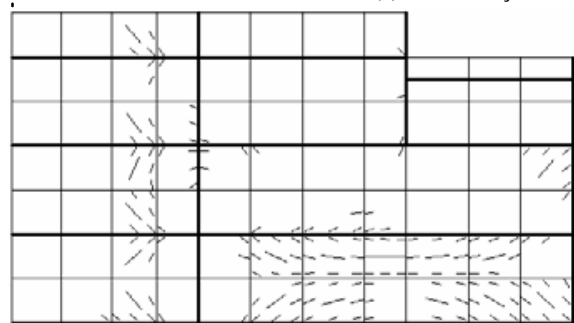

Figure 11. Predicted cracking patterns of top and bottom layers of floor slab at $20^{\circ} \mathrm{C}$ in the British Steel Corner Test for Case 1 (a, b) and Case 2 (c, d).

(a) Top Layer

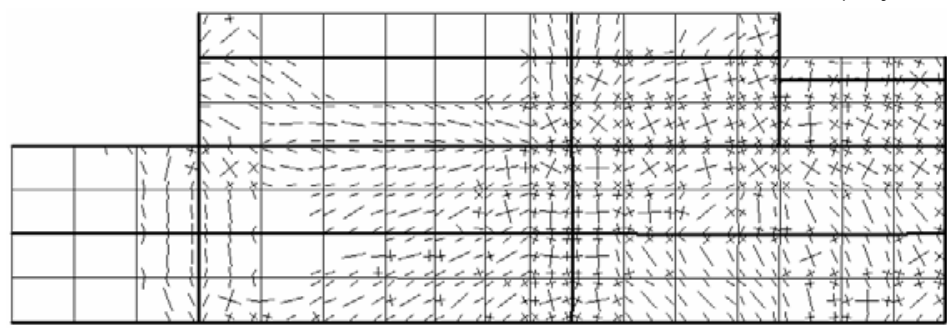

(b) Bottom Layer

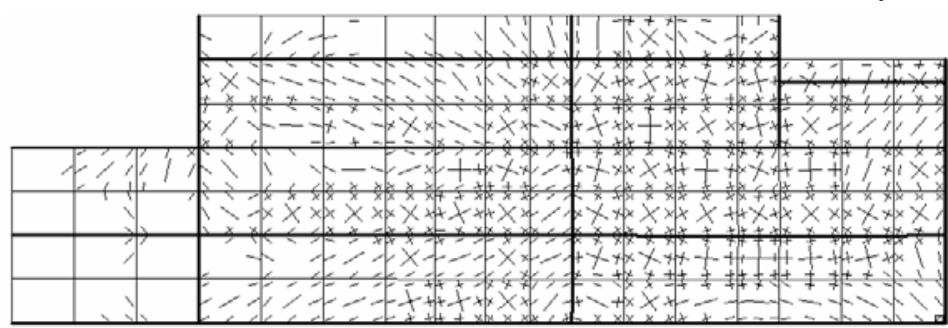

(c) Top Layer

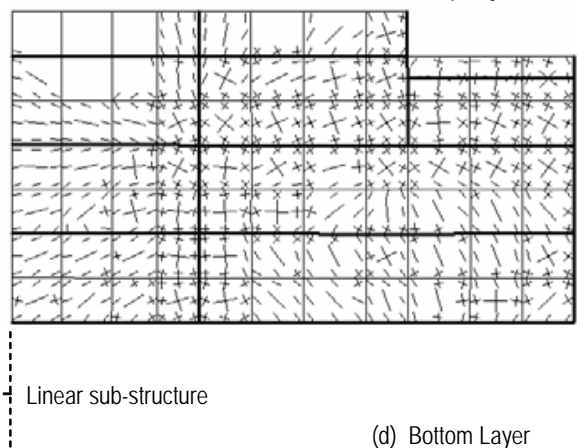

(d) Bottom Layer

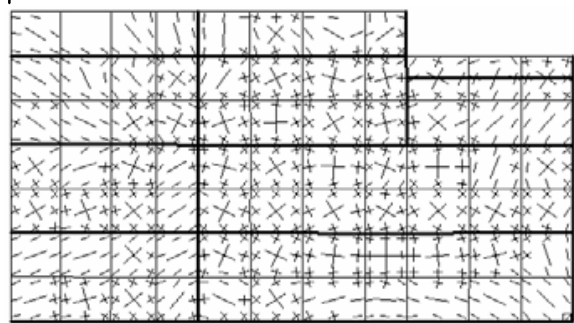

Figure 12. Predicted cracking patterns of top and bottom layers of floor slab at beam lower flange temperature $900^{\circ} \mathrm{C}$ in the British Steel Corner Test for Case 1 (a, b) and Case 2 (c, d). 
(a) $20^{\circ} \mathrm{C}$

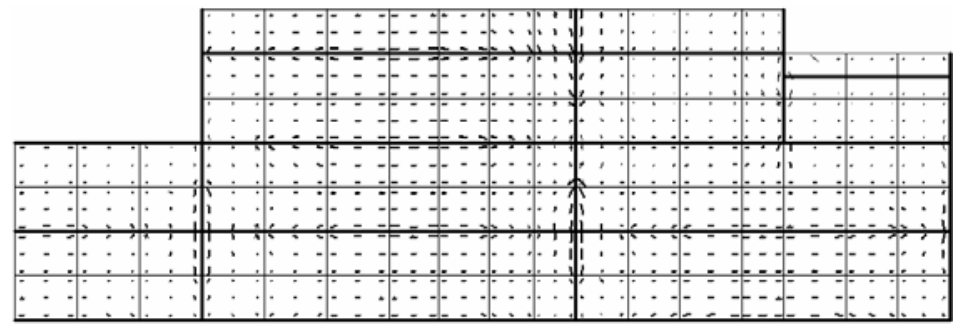

(b) $900^{\circ} \mathrm{C}$

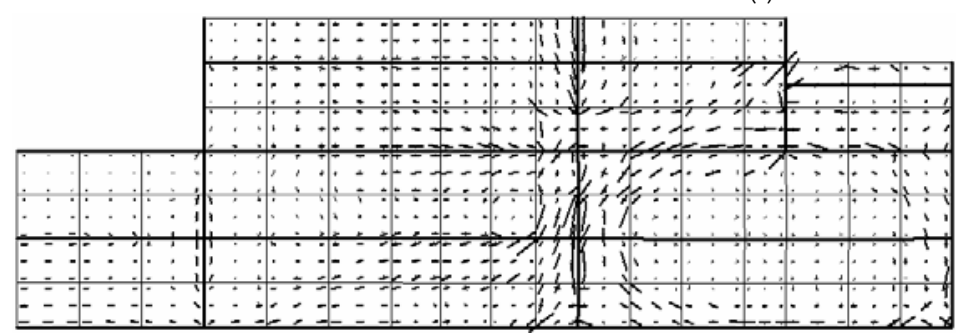

(c) $20^{\circ} \mathrm{C}$

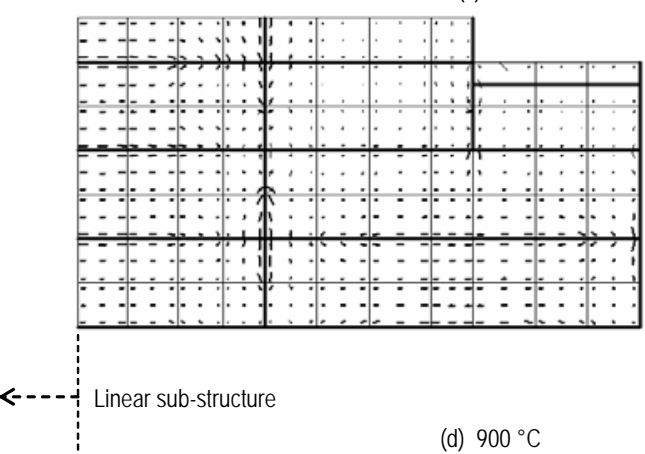

(d) $900^{\circ} \mathrm{C}$

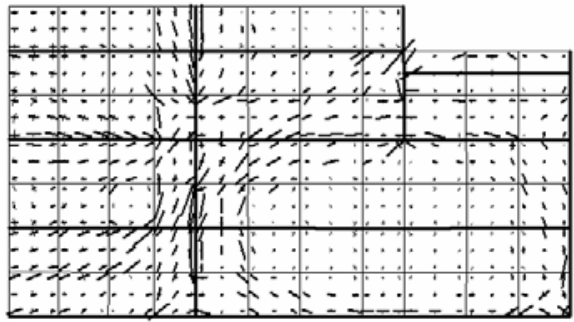

Figure 13. Predicted distribution of principal membrane tractions at $20^{\circ} \mathrm{C}$ and $900^{\circ} \mathrm{C}$ in the British Steel Corner Test for Case 1 (a, b) and Case 2 (c, d). (thick line=compression; thin line=tension).

Comparing Case 3 of the Corner Bay test with Case 4 of the Restrained Beam test, both represent extreme situations in which all elements outside the fire compartment are included within the elastic super-element. In the Corner Bay the fire zone was much more extensive than in the Restrained Beam Test so there was less opportunity for loads in the fire zone to be redistributed to the surrounding cool structure. Additionally, there was little in-plane restraint to thermal expansion of components within the fire compartment, whereas for the Restrained Beam Test a completely surrounding cool slab provided considerable restraint of this kind. It can be seen that the main influence of the surrounding cool structure was to provide structural continuity, especially in the concrete slab floors, to the two interior edges of the fire compartment. It is therefore logical that the Corner Bay Test results should be less affected by the modelling of the cool adjacent structure than were those from the Restrained Beam Test, so that Case 3 is modelled with almost the same accuracy as Case 1. This contrasts markedly with the Restrained Beam Test, in which thermal expansion is resisted and there is an obvious mechanism available for redistribution of loading.

\section{CONCLUSIONS}

This paper illustrates the use of the sub-structuring technique and a re-numbering algorithm to increase the efficiency of modelling the structural behaviour of buildings in fire conditions. In this process a user-defined cool region of the structure is sub-structured and condensed as a linear super-element with connecting nodes which interact with the non-linear sub-structure representing the fire zone, plus a border zone of unheated elements. The procedure has been incorporated into Vulcan and two full-scale fire tests have been modelled, both to show the computational efficiency of the method and to investigate the principles which control selection of super-elements. This depends on the way in which restraint from the surrounding structure resists thermal expansion of the fire compartment and provides support which diverts load paths away from the heated members. From the modelling of two full-scale fire tests it has been seen that, if the surrounding cool structure is capable of providing high restraint to thermal expansion of the fire compartment (as in the Restrained Beam Test), this has a very important influence on the behaviour of the heated structure. Of course, the structural continuity provided by the adjacent structure is also important. For fire compartments subjected to very little in-plane restraint (as in the British Steel Corner Test) 
structural continuity is the only major factor influencing the structural behaviour in the fire compartment. It is reasonable to conclude that, in order to achieve accurate analytical results for small fire compartments with high restraint from surrounding cool structure the non-linear mesh zone should extend well (at least three to four elements) beyond the fire compartment. However, for large fire compartments with little restraint the non-linear sub-structure can extend no further than the edges of the fire compartment.

It is evident that using this sub-structuring technique to represent the cool structure adjacent to a fire compartment is one of the building blocks in increasing the efficiency of modelling of structures in fire. The re-numbering procedure based on the model proposed by Burgess and Lai [16] is computationally efficient, and it is important when modelling three-dimensional building structures to attempt to create as optimal a numbering system as is feasible. The procedure proposed in this paper is a combination of sub-structuring and re-numbering, and should therefore maximise computational efficiency as much as possible for any given hardware and solution scheme. In the examples analysed savings of computing run-time of the order of 5 to 10 times were achieved. Within the Vulcan software the introduction of the frontal solution method into the super-element procedure also makes it capable of modelling very large problems without any difficulty.

\section{REFERENCES}

[1] “ISO 834: Fire resistance tests - elements of building construction", International Organisation for Standardisation, 1985.

[2] Najjar, S.R. and Burgess, I.W., "A non-linear analysis for three-dimensional steel frames in fire conditions”, Engineering Structures, 1996, 18(1), pp.77-89.

[3] Bailey, C.G., "Simulation of the structural behaviour of steel-framed buildings in fire”, $\mathrm{PhD}$ Thesis. University of Sheffield, 1995.

[4] Huang, Z., Burgess, I.W. and Plank, R.J., "Non-linear analysis of reinforced concrete slabs subjected to fire”, ACI Structural Journal, 1999, 96(1), pp.127-135.

[5] Huang, Z., Burgess, I.W. and Plank, R.J., "Influence of shear connectors on the behaviour of composite steel-framed buildings in fire", Journal of Constructional Steel Research, 1999, 51(3), pp.219-237.

[6] Huang, Z., Burgess, I.W. and Plank, R.J., "Modelling membrane action of concrete slabs in composite buildings in fire. Part I: Theoretical development", Journal of Structural Engineering, ASCE, 2003, 129(8), pp.1093-1102.

[7] Huang, Z., Burgess, I.W. and Plank, R.J., "Modelling membrane action of concrete slabs in composite buildings in fire. Part II: Validations”, Journal of Structural Engineering, ASCE, 2003, 129(8), pp.1103-1112.

[8] Huang, Z., Burgess, I.W. and Plank, R.J., “3D Modelling of beam-columns with general cross-sections in fire”, Structures in Fire, Proceedings of the Third International Workshop, Ottawa, Canada, 2004, pp.323-334.

[9] Huang, Z., Burgess, I.W. and Plank, R.J., "Modelling of six full-scale fire tests on a composite building”, The Structural Engineer, 2002, 80(19), pp.30-37.

[10] Dodds, R.H. and Lopez, L.A., "Sub-structuring in linear and non-linear analysis", International Journal for Numerical Methods in Engineering, 1980, 15, pp.583-597.

[11] Sheu, C.H. et al., "Application of the sub-structuring technique to non-linear dynamic structural analysis”, Computers \& Structures, 1990, 35(5), pp.593-601.

[12] Behin, Z. and Murray, D.W., "A sub-structure-frontal technique for cantilever erection analysis of cable-stayed bridges”, Computers \& Structures, 1992, 42(2), pp.145-157. 
[13] Liu, X.L. and Lam, Y.C., "Condensation algorithms for the regular mesh sub-structuring”, International Journal for Numerical Methods in Engineering, 1995, 38, pp.469-488.

[14] Bathe, K.J., “Finite element procedures”, Prentice-Hall Inc., New Jersey, 1996.

[15] Hinton, E. and Owen, D.R.J., "Finite element programming”, Academic Press, London, 1977.

[16] Burgess, I.W. and Lai, P.K.F., “A new node re-numbering algorithm for bandwidth reduction”, International Journal for Numerical Methods in Engineering, 1986, 23, pp.16931704.

[17] Gibbs, N.E., Poole, W.G. and Stockmeyer, P.K., "An algorithm for reducing the bandwidth and profile of a sparse matrix”, SIAM Journal of Numerical Analysis, 1976, 13, pp.236250.

[18] Cuthill, E.H. and McKee, J.M., "Reducing the bandwidth of sparse symmetric matrices", Proceeding of 24th National Conference ACM., Barndon Systems Press, New Jersey, 1969, pp.157-172.

[19] Cheng, K.Y., "Note on minimizing the bandwidth of sparse symmetric matrices", Computing, 1973, 11, pp.27-30.

[20] Bentley, P.K., Shaw, D. and Tomlinson, I., "ECSC project: behaviour of a multi-storey steel framed building subjected to natural fires. Test 1: restrained beam, data files: temperature measurements”, Report S423/1/Part T1, Swinden Technology Centre, British Steel plc, Rotherham, UK, 1995.

[21] Bentley, P.K., Shaw, D. and Tomlinson, L., "ECSC project: behaviour of a multi-storey steel framed building subjected to natural fires. Test 1: restrained beam, data files: deflection measurements”, Report S423/1/Part D1, Swinden Technology Centre, British Steel plc, Rotherham, UK, 1995.

[22] Bann, M.S., Bentley, P.K., Shaw, D. and Tomlinson, L., "ECSC project: behaviour of a multi-storey steel framed building subjected to natural fires. Test 3: corner compartment, data files: temperature measurements”, Report S423/3/Part T1-T3, Swinden Technology Centre, British Steel plc, Rotherham, UK, 1996.

[23] Bentley, P.K., Shaw, D. and Tomlinson, L., "ECSC project: behaviour of a multi-storey steel framed building subjected to natural fires. Test 3: corner compartment, data files: deflection/displacement measurements”, Report S423/3/Part D1, Swinden Technology Centre, British Steel plc, Rotherham, UK, 1996. 